\title{
"Creating an information technology and communication and knowledge-driven research in Sefako Makgatho Health Sciences University"
}

$\begin{array}{ll} & \text { Tichavasia Alex Dandadzi } \\ \text { SOITHORS } & \text { Taurai Hungwe } \\ & \text { Taurshonisa Seeletse }\end{array}$

Tichavasia Alex Dandadzi, Solly Matshonisa Seeletse and Taurai Hungwe

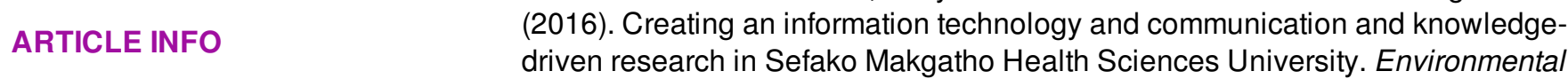
Economics, 7(1), 40-46. doi: 10.21511/ee.07(1).2016.05

DOI http://dx.doi.org/10.21511/ee.07(1).2016.05

RELEASED ON Thursday, 24 March 2016

JOURNAL "Environmental Economics"

FOUNDER LLC "Consulting Publishing Company "Business Perspectives"

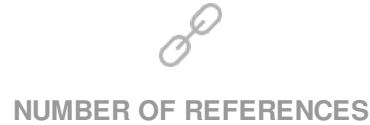

0

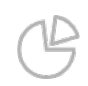

NUMBER OF FIGURES

0

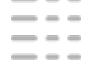

NUMBER OF TABLES

0

(C) The author(s) 2021. This publication is an open access article. 
Tichavasia Alex Dandadzi (South Africa), Solly Matshonisa Seeletse (South Africa), Taurai Hungwe (South Africa)

\title{
Creating an information technology and communication and knowledge-driven research in Sefako Makgatho Health Sciences University
}

\begin{abstract}
The paper addresses the low research standing of Sefako Makgatho Health Sciences University (SMU). SMU is a university established on $1^{\text {st }}$ January 2015 in the Gauteng Province of South Africa. Its weaknesses were inherited through history. The former Medical University of Sothern Africa (MEDUNSA) and University of Limpopo (UL) are the SMU's predecessor universities from which SMU emerged. One main weakness is that UL appointed managers on Medunsa campus to head divisions but disregarding merit. Hence, many current SMU managers do not necessarily possess the qualities required for a research campus that is technology dominated. In particular, some staff and managerial appointments made prior to the SMU formation, which SMU had to inherit are the causes of deficiencies in SMU's research and information development. The paper develops an approach for SMU to enable existing resources of information technology and communication (ICT) and statistical sciences to improve research on SMU campus. The approach developed is robust. It also has a built-in monitoring evaluation and control element. Benchmarks are used in the method development.
\end{abstract}

Keywords: benchmarks, human resources, KBE, monitoring and control, robust, staffing.

JEL Classification: D7, D8, M5, O2, O3.

\section{Introduction}

Economies of developed nations matured due to research, technology and information, among others. They became known as knowledge-based economies (KBEs), and did much to avoid reliance on out-of-date resources and methods. Research leads to the creation of new knowledge when blended properly with correct approaches and technology (Young, 2008). The results lead to innovation and technological revolution which in turn inspire development and progress in such countries. Educational institutions play a boundless role in this aspect. They lead the creation and dissemination of knowledge. Academic activities that are based on new knowledge have a chance to stimulate national economic growth. In almost every country where research is decent and used correctly, there is economic growth. Such countries enable justified provision of higher job remunerations and many employment opportunities. They are also competitive in their continents as well as at the global level. The progressive economic trends in developed countries hinge intensely on new technology investments, high-technology industries and highly skilled labor among others. These are indispensable $\mathrm{KBE}$ constituents.

(C) Tichavasia Alex Dandadzi, Solly Matshonisa Seeletse, Taurai Hungwe, 2016.

Tichavasia Alex Dandadzi, Department of Computer Sciences, Sefako Makgatho Health Sciences University, South Africa.

Solly Matshonisa Seeletse, Professor of Operations Research, Department of Statistics and Operations Research, Sefako Makgatho Health Sciences University, South Africa.

Taurai Hungwe, Department of Computer Science, Sefako Makgatho Health Sciences University, South Africa.
Innovation stimulates economic growth and national development. Institutions of higher learning (such as universities and universities of technology in the case of South Africa) are supposed to be leading research and innovation. However, Wolf (2006) stated that many of South African academic institutions perform poorly in these aspects. Several reasons exist for this, one being the placement of incapable managers at top positions.

Thus, technological globalization presents advancement opportunities. Some countries do not exploit these opportunities. Archibugi and Pietrobelli (2002) counsel that thoughtful efforts, coupled with proper government actions, are essential to embrace innovation for economic growth. For developing countries to build their potential as KBEs there should be investments in human capital. The starting point of human capital investment is education. A highly skilled workforce and high-technology infrastructure industries are also essential. This justifies that South African higher education institutions (HEIs) should nurture scientifictechnological partnerships and networks with industries and sectors outside academia, as well as with institutions in developed countries. These blends and conglomerates will heighten the competitiveness and international trade prospects of firms in South Africa.

\section{Conversation context}

Sefako Makgatho Health Sciences University (SMU) was established in Gauteng Province of South Africa on the $1^{\text {st }}$ of January 2015 in the former Medunsa campus of the University of Limpopo (UL). UL had been established in 2005 from the merger of the former Medical University of South- 
ern Africa (MEDUNSA) and the former University of the North. At its inception, SMU had only one Faculty of Medicine below which several schools existed. SMU had a school (pathology and preclinical sciences) housing departments in several natural and mathematical sciences, which include computer science and statistics. Dominance in course offering within SMU is in the health and medical sciences. These sciences develop service providers in their fields in large numbers, but mainly at the undergraduate levels. Departments are divisions under the schools. Clusters of some departments existed for control in which management at cluster levels had a higher status than those at unit levels. Statistics and Operations Research (SOR) appeared as a unit in the Mathematical and Physical Sciences (MPS) department. MPS was a cluster of several departments (Chemistry, Computer Science, Mathematics, Physics and Statistics). Thus, Computer Science was also a unit under the MPS cluster. The work demands in these units were equally and sometimes more demanding as the work of heads of departments managing clusters.

Research within SMU was supported mainly by the sciences such as Computer Science and Statistics. The problem was that these departments were poorly resourced. They were allocated least student numbers and fewest academics. They also did not have administrative or any support staff. The school management had thus far failed to show that it was knowledgeable in the potential of IT and statistics. IT and statistics, especially when coupled with operations research, can enhance innovation and also provide knowledge required for KBEs (Moeller \& Reitzes, 2011). Global, continental and national benchmarks exist which show that these mathematical and computational sciences are valuable in leading innovation and technology. This paper develops a model for an ICT-driven knowledge-base (KB) for research in SMU. There is limited technological support for researchers on SMU campus. However, research support from the statistics department is already taking place on SMU campus.

SMU is dominated by health and medical sciences. It has its own academic hospital, the Dr. George Mukhari Academic Hospital. The dominance of health and medicine in SMU pressurises that this offering be leading the campus in research and postgraduate productivity. The academic hospital is a huge opportunity for experimental research on patients, such as the clinical trials.

1.1. SMU science and technology department. South African science and technology introduced many policies since the democracy dawn of year 1994. According to Department of Science and
Technology (DST, 2008), the aim of these policies is to propel South Africa's makeover to a KBE. Policies are strategic instruments for transformation. In the case of DST policies, they were designed as a framework for knowledge and innovation to become crucial constituents for economic growth and development. The ultimate resultant was for South Africa to be globally competitive. DST missed an opportunity at SMU inception to invest in science and technology (S\&T). The ministers of higher education and health were instrumental in the modelling and the formative development of SMU. If DST had been effectively participating in SMU establishment, opportunities for infrastructure development for the sciences could have probably been identified at an early stage. However, the DST's National Research Foundation (NRF) sponsors South African S\&T academic researchers. NRF has supported S\&T researchers immensely at SMU. This paper develops a S\&T model for a technological knowledge-driven framework for research in SMU.

1.2. Benchmarks. Measures of level of progress have limited or no significance when considered in segregation. However, when compared with measures in similar circumstances they tend to make more sense. An example is using an in-house journal when academics publish their research. This does not say much about the message's importance when gauged at global level. Meaningful researches conducted at national and international levels display progress. Globalization is setting trends because no country develops in isolation, and all countries' activities, development and progress are measured against one another. Benchmarks are indices that institutions, groups and individuals can use to measure their progress relative to the leading counterparts (Newman et al., 2008). The purpose of research and innovation is to use benchmarks to improve. The ultimate intent is to reach the maximum performance which the leading experts have demonstrated to be conceivable. The other benefit of benchmarks is that emulation is possible.

There is no need to search for completely new ways of doing things. For SMU, research benchmarks in which knowledge derive from statistical and technological support exist in South African leading universities such as Cape Town, Free State, Johannesburg, KwaZulu-Natal, North-West, Pretoria, Rhodes, South Africa, Stellenbosch, and Witwatersrand (QS Top Universities, 2015). These benchmarks are used to the point where it practically applies in SMU. These benchmark universities employ capable academic recruits, use proper human resources procedures, depend on time-driven information technology and communication (ICT) policies 
and practices, and the academics are competent and ever-advancing, among other attributes. This is not always clear in some universities where deficiencies exist in the processes of recruiting academics.

1.3. Robust approach. Many programs of development in South Africa have failed since democracy dawn of year 1994 (Duffield, Raisbeck \& Xu, 2008). Several examples of programs that failed include the Reconstruction and Development Program, private-public partnerships, delivery of services to the people, poverty reduction, corruption eradication, education blowout, and many others. The main reason was that the efforts were not robust, which means that they were sensitive to external influences other than those intended for the planned program. Experience shows that even good plans and preparations do not guarantee successful results. However, use of robust methods, which, according to Anderson (2008), can resist effects of bad influences, can assist in curbing such influences. The reason to incorporate robustness in this study is to strengthen the model developed.

\section{Human resources requirements for ICT and knowledge research}

One SMU problem is that SMU inherited personnel who had been placed by UL to serve UL interests. Some of those interests were not necessarily beneficial to the Medunsa campus at the period of UL, and are certainly not serving SMU interests. Many of these incumbents became burdens to the SMU development. Further, the law required that they serve the terms given to them by UL, especially when new SMU policies had not been designed (South Africa, 2014). As a result, SMU development pace is slow in some areas and non-existent in others. SMU did not need many of UL resources, as many in leading positions could have been rejected in a visionary SMU that needed genuinely capable leaders in leadership positions. The leading SMU staff should be able to communicate with their constituencies, show their own visions and also be able to gather ideas in growing their divisions on campus. They should also be able to mentor and grow those below them. Many of the UL inherited managers did not show to possess these attributes.

2.1. Staffing at strategic level. The top managers in academic schools should be able to understand the value of each of the departments which they lead. Often, the school leaderships knew and appreciated only their own home departments (i.e. departments which employed them first time when they were recruited). Some then used the platform above departmental level to give advantages to thir home departments, often at the expense of other depart- ments. Unfortunately, many who served at the SMU school leaderships seemed to be technology-illiterate and showed little contribution in research. Therefore, they had not been able to appreciate research drivers, and had in some cases undermined the desires of these departments to grow by refusing to support their proposals for staffing and resourcing. The benchmarks stated earlier, are local universities in various provinces of South Africa. The deans and school leaderships in these benchmark universities have generally shown to be exemplary active producers of research outputs, supervisors of postgraduate students, participants at national and international conferences, capable users of technological resources, and leaders who also understood the language of research (Jhurreev, 2005). The new SMU could not have such a luxury because of the inherited incapacities from UL.

The participants at school leadership level (and higher) should be subjected to a school congregation in which they present and debate their visions for growth and constituency support. The winning candidates should be required to sign a performance contract which must be monitored closely. Once in service, the incumbents should be required to submit regular reports of progress and evidence of achievements. If satisfactory progress is not shown, consideration of removing the incumbent should be high. In case where no candidate qualifies after the presentations, outside recruitment and headhunting should be strongly considered. This will be to avoid mediocrity compromises. When ideal candidates are not found after extensive searches, rotations of short durations should be considered from departmental heads.

2.2. Human resources at departmental level. The departments in mathematical and computer sciences have suffered the same treatment under UL as the management levels under which they served. Cases where merit was not used in appointing managers existed in which undeserving recruits were imposed to lead some of these departments. As a result, some departments inherited mediocrity that polluted excellence in academic appointments. These examples were evident even in understaffed departments. However, there were still worthy academic in these departments who came through pure merit. The position at departmental level is that for technology and resourcefulness in research, only worthy computer science and statistics experts should be recruited in these departments (CARICOM, 2014).

\section{Method}

The study was exploratory research (Cooper \& Schindler, 2003) to determine the way SMU's research was done and supported. It then used some successful benchmarks for a comparative analysis. 
The basis for comparison was how technological and statistical supports were used to enhance research in the context of a South African HEI, as well as the context of a medical school with an academic hospital facility. This forceful structure is what SMU was expected to be, and which offers an academic advantage that other South African HEIs do not possess. The method of this study also benefitted from the model developed by Dandadzi (2014) which showed how technology could support administrative and academic activities for the sciences in SMU. It also biases towards the advantages exposed in a Maesela (2015) study which emphasized that holistic approaches should be used to enhance success in a venture of any kind. The methods were also used by Bell, Crick and Young (2004) to develop strategies for knowledge-intensive enterprises for small businesses in the United Kingdom.

\section{Findings}

The level of research in SMU was much lower than the levels shown in leading universities of South Africa. This low research level was also lower than the levels shown in small universities in the country. In particular, QS Top Universities (2015) demonstrated that the level of research in SMU was among the lowest in the country. This trend had been prevailing since the historical days of MEDUNSA and as a campus of UL.

The study also showed that researchers on SMU campus performed research in isolation. There was competition of departments and colleagues within SMU when there was an opportunity for the formations of partnerships and collaborations. Generally, collaborations of SMU researchers seemed nonexistent since the different researchers performed their researches in isolation.

Another perceived research deficiency was that many of the campus researchers seemed to repeat the researches done in the past using newly collected data. This seemed to be due to limited use of technology which could indicate the insignificances of such researches.

Non-experts in statistics planned their own researches in the way they were taught to plan research by their own supervisors when they were students. They also performed their own analyses, and did not ask for statistical checks on their statistical methods. One major impression was that they seemed to miss the improvements and developments in statistical literature, such as the theory of outliers and robust methods.

Also, older academics seemed to be the ones supervising more. This was therefore to demonstrating that outdated methods were dominant in the SMU researches produced.

The other concern was that there was not much information given about how clinical trials were conducted in SMU. This was particularly regarding technology and statistics expertise involvement, as well as how far the results of clinical trials led to improving health and lives in the areas of SMU's jurisdiction. In particular, technology was not effectively used. Also, many older academics and researchers were not adequately computer literate. This showed that research in SMU lacked in their association with technology and statistics. This rendered the SMU research to lack in KBE quality.

\section{Development of an ICT and knowledge research}

The levels of knowledge in computer science and statistics for medical and health science students at SMU are low, generally. If the analyses of their researches require high knowledge levels of these courses, then their researches will also always be restricted. For advancement and effectiveness of the researches undertaken, some researches require advanced levels of statistics and technology. These will not be possible without consulting experts in these fields. Therefore, in SMU, the department dealing with statistics and statistical methods, and the one dealing with technology are necessary to offset the statistics and technology inadequacy intrinsic in the training of health sciences and medicine in SMU. Technology can assist to ensure that there are no duplication of researches, and that the level of importance of each study undertaken justifies the study. When a study shows to lack value, or its perceived value lacks impact, then such a study can be withdrawn or upgraded to ensure that it is worthy. Currently, many researchers in these fields undertake research mainly to qualify for their degrees, but not necessarily to add value to real life cases. Once the proposed study shows to be worthwhile, then statistical methods can assist to design appropriate studies. The involvement of statistical methods is to ensure that designs planned are adequate, and that the methods used are immaculate.

5.1. Strategic level. The vision identified at departmental levels should also be understood and appreciated at the strategic levels. In SMU sense, this means that the school leadership should know the extent to which the different fields can contribute to various life and research aspects. In particular, the school leadership should know the extent to which technology and statistics can assist research at academic and real life levels. The synergy of statistics and technology can be identified by that while sta- 
tistics can design a measure for research worth, technology can develop quicker methods to search for data and together they can be used in evaluating each research (Gillwald, Moyo \& Stork, 2012). The school leadership level should make sure that these departments are well resourced, from experienced, capable statistics experts to up-and-coming and leading junior academics who can do research and also support other researchers. The level at which SMU research support operates in terms of human resources, equipment and other aspects of research shows to be far below the extent to which it happens in the benchmark universities.

5.2. Resourcefulness at departmental level. The statistics and computer science departments should be able to work together because their optimal worth depends mainly on their capability to partner on the same research projects. Leading practitioners in these departments should be capable experts in their fields. On SMU campus this is visible. The work they do should be sustainable because advancement in these fields will only be captured by the departments involved. That is, researchers can only match developments in their fields while technology and statistics can be up-to-date with development in statistics and technology. Also, development in statistics and technology will come with new methods possessed by up-andcoming and new experts in the fields. Hence, succession plans should be designed in the departments to cater for lecturing activities, research support and undertaking research. Currently there are no succession plans because the departments are still attempting to grow. Also, support from the school leadership level is deficient. Furthermore, the vision of these departments to assist SMU and its researchers is not necessarily shared by the school leadership.

\section{Discussion}

The school of pathology and pre-clinical sciences leadership was among the inherited human resources bundles from UL. Seemingly, they were not properly recruited, but were appointed by UL to serve the interests of UL. After SMU formation, the ULappointed management did not show the necessary support for the development, growth and standing of the computer science and statistics department. These two departments had proactively started to provide research services at a low scale because of their understaffing conditions. They had the vision to grow and be sustainable for both lecturing and research support. They need resources in the form of capable experienced lecturers and capable young lecturers for current services and succession planning that would enable service sustainability. They knew also that they needed succession plans.
The computer science and statistics at SMU operated at a low level in both research and research support compared to the benchmarks. The structures existed in those benchmark universities, while at SMU it was the initiatives of the departments to perform the tasks.

The Computer Science and Statistics departments were both well equipped to carry out minimal services. However, with lack of support from higher ranks they could not grow as they envisioned. The two departments had, however, started to offer the necessary research services at low levels due to their determination to grow. They wanted to grow, to participate in research, to engage in succession planning activities, and had also started to partner together to form the synergies needed for researchers.

\section{Recommendations}

Some recommendations are made from this study. These are:

- SMU human resources policies and practices should be customized for developing SMU and its holistic (i.e., learning and teaching; research \& community engagement) academic progress.

- SMU academic managers in leadership positions should be trained in management and leadership, and should also be prepared and conditioned for ICT rollout.

- Monitoring and control should be done at all the stages of the ICT rollout for research to create a technology-driven environment.

- Financial investments in technology should be made adequately in SMU, and with justification of long-term future returns.

- Statistical support should be capacitated and supported with resources as benchmarked from leading local universities.

- SMU should ensure that campus research for students and academics has the necessary technological and statistical support.

- Younger technology-era researchers and more experienced older researchers should also partner and collaborate to produce research synergies that can provide improvements in peoples' lives and enhance succession plans for new/emerging researchers.

- In addition, SMU should improve technology applications in its influential activities.

- Every ICT plan in SMU should have a robust method build-in to prevent failure.

- Effective succession plan should be introduced and activated in SMU, particularly in Computer Science and Statistics. 


\section{Conclusion}

SMU was deficient in research, in technology and in statistical support for researchers. Some academic managers in SMU had limited technology knowledge, and supported technology minimally. The study showed that SMU had an opportunity at its formative early years to develop its technology base and statistical support for research, especially which aim was to make SMU a university with high output of research. The managers should be both trained and conditioned to support the technological and statistical initiatives of improving research. Use of technology and statistics together can ensure accurate knowledge that researchers need to produce more research output for improving human life.
Monitoring and control are also important at every stage of the ICT and KB development process. Also, robust methods are necessary to ensure that investments made produce the results intended by the plans.

A proposed model for research in SMU could be summarized in the form of a figure (see in Appendix).

\section{Acknowledgements}

The authors acknowledge the support and contributions of the Departments of Statistics and Operations Research for leading the artificial intelligence studies and projects; as well as the Department of Computer Science for developing the e-supports in the joint projects for the Department of Mathematical and Computational Sciences in SMU.

\section{References}

1. Andersen, R. (2008). Modern methods for robust regression. Thousand Oaks: Sage.

2. Archibugi, D. \& Pietrobelli, C. (2002). The globalisation of +technology and its implications for developing countries: Windows of opportunity or further burden? Technology Forecasting \& Social Change, 70, pp. 851-883.

3. Bell, J., Crick, D. \& Young, S. (2004). Small firm internationalization and business strategy: An exploratory study of 'knowledge-intensive' and 'traditional' manufacturing firms in the UK, International Small Business Journal, 22, pp. 23-26.

4. CARICOM (Caribbean Community, 2014) CARICOM ICT Statistics and Indicators 2000-2012. Statistics SubProgramme Caribbean Community (CARICOM) Secretariat, April 2014.

5. Cooper, D. \& Schindler, P. (2003). Business research methods. New York: McGraw Hill.

6. Dandadzi, T.A. (2014). Artificial intelligence modelling in selection problems. PhD thesis, University of Limpopo Medunsa Campus, Pretoria, Gauteng Province, South Africa.

7. DST (Department of Science and Technology). (2008). Ten Year Innovation Plan: Innovation towards a knowledge-based economy 2008-2018. Pretoria: DST.

8. Gillwald, A., Moyo, M. \& Stork, C. (2012). Understanding what is happening in ICT in South Africa. Cape Town: Research ICT Africa.

9. Jhurreev, V. (2005). Technology integration in education in developing countries: Guidelines to policy makers, International Education Journal, 6(4) pp. 467-483.

10. Maesela, P.S. (2015). Evaluating the business models that foreign business owners use to succeed in South Africa. BSc Honours dissertation, Sefako Makgatho Health Sciences University, Pretoria, Gauteng Province, South Africa.

11. Moeller, B. \& Reitzes, T. (2011). Education Development Center, Inc. (EDC). Integrating technology with student-centered learning. Quincy, MA: Nellie Mae Education Foundation.

12. Newman, J., Azevedo, J.P., Saavedra, J. \& Molina, E. (2008). The real bottom line: Benchmarking performance in poverty reduction in Latin America and the Caribbean. Washington, D.C.: World Bank, LCSPP.

13. Powell, W.W. \& Snellman, K. (2004). The knowledge economy, Annual Review of Sociology, 30, pp. 199-220.

14. QS Top Universities. (2015). Top 10 Universities in South Africa 2015. Cape Town: BRICS.

15. South Africa. (2014). Government Gazette, Act No 47 of 2013, Employment Equity Amendment Act 2013, Cape Town: The Precedency.

16. Wolf, S. (2006). Encouraging innovation and productivity growth in Africa to create decent jobs. Paper presented The DPRU/TIPS Coherence held in October $18^{\text {th }}$ to $20^{\text {th }} 2006$ in Johannesburg, South Africa.

17. Young, M.F.D. (2008). Bringing knowledge back in. Oxon: Routledge. 
Appendix

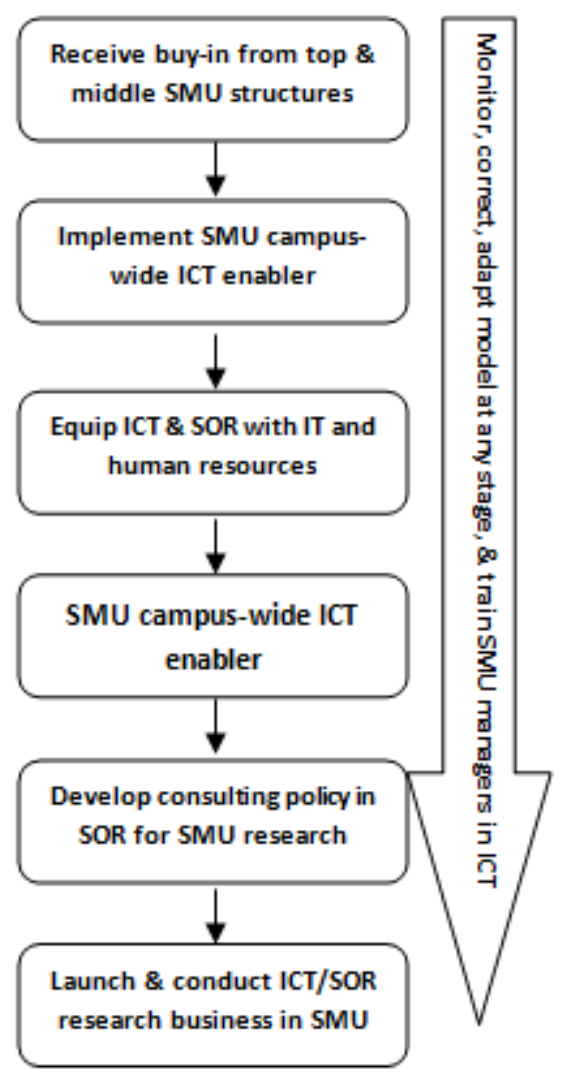

Fig. 1. Robust SMU KB model for research 